\title{
Study of the Synthesis and Characterization of Methacrylate Photoresists
}

\author{
S. C. FU, ${ }^{1}$ H. W. LIN, ${ }^{2}$ W. Y. CHOU, ${ }^{1}$ L. A. WANG, $^{3}$ K. H. HSIEH ${ }^{1}$ \\ ${ }^{1}$ Department of Chemical Engineering, National Taiwan University, Taipei 10617, Taiwan \\ ${ }^{2}$ Graduate Institute of Material Science and Engineering, National Taiwan University, Taipei 10617, Taiwan \\ ${ }^{3}$ Graduate Institute of Electro-Optical Engineering, National Taiwan University, Taipei 10617, Taiwan
}

Received 28 March 2000; accepted 9 February 2001

\begin{abstract}
Polymethacrylate copolymers used as single-layer resists (SLR) were investigated in this study. A photoacid generator (PAG) in the chemically amplified resist (CAR) can generate a Brönsted proton after light stimulation, which can catalyze the deprotection reaction of $t$-butyl methacrylate during the postexposure baking (PEB) process. Excimer lasers ( $\mathrm{KrF}$ and $\mathrm{ArF}$ ) were used as light source to evaluate the lithographic performance of resists. The hydrophobic property of the resist changed to hydrophilic property after the deprotection reaction by light exposure, which made the exposed resist soluble in the base developer. The deprotection reaction was analyzed by using FTIR and the reaction kinetics of the resist is discussed. The effects of the $t$-butyl methacrylate and the isobornyl methacrylate in the resists on the light sensitivity, contrast, reactive ion etching (RIE) resistance, and lithographic performance were systematically investigated. @ 2002 John Wiley \& Sons, Inc. J Appl Polym Sci 83: 1860-1869, 2002
\end{abstract}

Key words: methacrylate resists; chemical amplification; deprotection reaction; contrast; lithography

\section{INTRODUCTION}

The increasing progress in integrated circuit (IC) manufacture has brought great convenience and efficiency to human life. The increased complexity and enhanced reliability of the advanced IC requires the producer to manufacture the circuit with more and more stringent line width. However, to construct a thinner critical dimension (CD) in the circuit, both the resists and the light source must be modified or changed. For light interference limitation, the light source required to expose the resist has to move from visible light

Correspondence to: K. H. Hsieh (khhsieh@ccms. ntu.edu.tw).

Journal of Applied Polymer Science, Vol. 83, 1860-1869 (2002)

๑ 2002 John Wiley \& Sons, Inc.

DOI 10.1002/app.2313 (g-line, i-line) toward $\mathrm{KrF}$ (248 nm) and $\mathrm{ArF}$ (193 $\mathrm{nm}$ ). Because of strong phenolic absorption in the phenolic-containing resists at $193 \mathrm{~nm}$, the Novolac and poly(4-hydroxystyrene) (PHS) resists, which are conventionally used in i-line and $\mathrm{KrF}$ (248 $\mathrm{nm})$, respectively, cannot be used as $\mathrm{ArF}$ $(193 \mathrm{~nm})$ photoresists.

To research resolution for this problem, IBM and Lincoln researchers ${ }^{1,2}$ first developed the methacrylate copolymers for a chemically amplified resist (CAR) used in 193-nm lithography. The $t$-butyl group in methacrylate copolymer can change the polarity after the postexposure baking (PEB) process. The exposed resist becomes soluble in the basic developer and exhibits the positive-tone pattern transferring. The photoacid generator (PAG) in the resist needs energy from light 
Table I Composition and Properties of Photoresist Copolymers

\begin{tabular}{|c|c|c|c|c|c|c|c|c|c|}
\hline Resist & MAA & MMA & TBMA & IBMA & $\begin{array}{c}\text { AIBN } \\
(\mathrm{mol} \%)\end{array}$ & $M_{w}$ & $\begin{array}{l}T_{g} \\
\left({ }^{\circ} \mathrm{C}\right)\end{array}$ & $\gamma$ & $\begin{array}{c}E_{0} \\
\left(\mathrm{~mJ} / \mathrm{cm}^{2}\right)\end{array}$ \\
\hline$A$ & 20 & 50 & 30 & 0 & 0.5 & 70,600 & 135.6 & 6.0 & 9 \\
\hline$B$ & 20 & 40 & 30 & 10 & 0.5 & 64,300 & 147.3 & 5.6 & 13 \\
\hline$C$ & 20 & 30 & 30 & 20 & 0.5 & 79,000 & 156.2 & 5.3 & 27 \\
\hline$D$ & 20 & 20 & 30 & 30 & 0.5 & 68,000 & 167.3 & 4.6 & 30 \\
\hline$E$ & 20 & 10 & 30 & 40 & 0.5 & 79,000 & 173.7 & 3.6 & 58 \\
\hline$F$ & 20 & 0 & 30 & 50 & 0.5 & 74,000 & 175.8 & - & - \\
\hline$G$ & 20 & 40 & 40 & 0 & 0.5 & 72,000 & 141.8 & 14.9 & 22 \\
\hline$H$ & 20 & 30 & 50 & 0 & 0.5 & 76,000 & 131.5 & 17.2 & 26 \\
\hline
\end{tabular}

exposure to activate the deprotection reaction, and can magnify the reaction concentration by repeatedly catalyzing the deprotection reaction of the photoresist. ${ }^{3-6}$

Investigations on the methacrylate CAR have mainly focused on improving the etching resistance by incorporating the high alicyclic groups, ${ }^{10,11}$ such as isobornyl, ${ }^{5}$ adamantyl, ${ }^{11}$ or the tricyclodecyl ${ }^{12}$ groups, or on developing a better latitude by changing the protective groups, such as tetrahydrofuranyl, ${ }^{13}$ ethoxyethyl, ${ }^{14}$ or the mevalonic lactone ${ }^{15}$ groups. Moreover, the rate of acid diffusion, about $10^{-6} \mu \mathrm{m}^{2} / \mathrm{s}$ in resists, is believed to be an important factor that influences the line width in lithography. ${ }^{16,17}$ The diffusionreaction models proposed by researchers have been integrated into the computer package Prolith, ${ }^{18}$ which has been widely used to predict the effect of processing conditions on the lithographic performance of resists. ${ }^{19,20}$ However, the effect of alicyclic groups in isobornyl methacrylate (IBMA) on lithography cannot be clearly understood from previous investigations, ${ }^{4,21-23}$ and the effect of deprotection groups in resists has not been clearly investigated. This work aims to investigate the lithographic performance of the copolymers from $t$-butyl methacrylate (TBMA), IBMA, methacrylic acid (MAA), and methyl methacrylate (MMA). Copolymers were synthesized with varying compositions of IBMA and TBMA, whose effects on light sensitivity, contrast, reactive ion etching (RIE) resistance, and lithographic performance are systematically discussed in the study.

\section{EXPERIMENTAL}

\section{Materials}

The monomers MMA, MAA, TBMA, and IBMA were purified by vacuum distillation to remove the inhibitor. Methacrylate copolymers of varying compositions were prepared by adding an appropriate equivalent amount of monomers (MAA, TBMA, MMA, MAA) in dry THF, with 2,2' -azobisisobutyronitrile (AIBN) as initiator (Table I). The reaction was carried out at $65^{\circ} \mathrm{C}$ under a nitrogen atmosphere over $24 \mathrm{~h}$. The copolymers were precipitated by using nonsolvent hexane and then dried in vacuum.

\section{Measurement}

The Fourier transform infrared (FTIR) analysis was carried out on a Bio-Rad FTS-40 (Bio-Rad, Hercules, CA). Thermal properties were obtained by using Perkin-Elmer DSC-7 and TGA-7 (Perkin Elmer Cetus Instruments, Norwalk, CT). Gel permeation chromatography (GPC) was performed on a Showa Shodex RI-71 (Showa, Japan) using THF as solvent. Hitachi S-800 SEM (Hitachi, Tokyo, Japan) was used to investigate the lithographic performance of the resist. Lambda-physik excimer lasers or Oriel 6810 mercury-arc lamp (Oriel, Stratford, CT) equipped with 254-nm band-passing filter was used as the exposure tool for the investigation. RIE resistance was conducted using a Roth and RAU Unilab RIE instrument. Film thickness was measured by using Dektak 3030ST surface profiler.

\section{Lithographic Evaluation}

Methacrylate copolymers mixed with $5 \mathrm{wt} \%$ PAG (triarylsulfonium hexafluoro-antimonate) were dissolved in 2-(1-methoxy)propyl acetate (PGMEA) and were filtered through a $0.2-\mu \mathrm{m}$ filter. Wafers used in the experiment were primed with hexamethyldisilazane (HMDS) for better adhesion properties. Resists were spin-coated on the wafers and then prebaked at $100^{\circ} \mathrm{C}$ for $1 \mathrm{~min}$. The thickness was controlled by varying the solution 


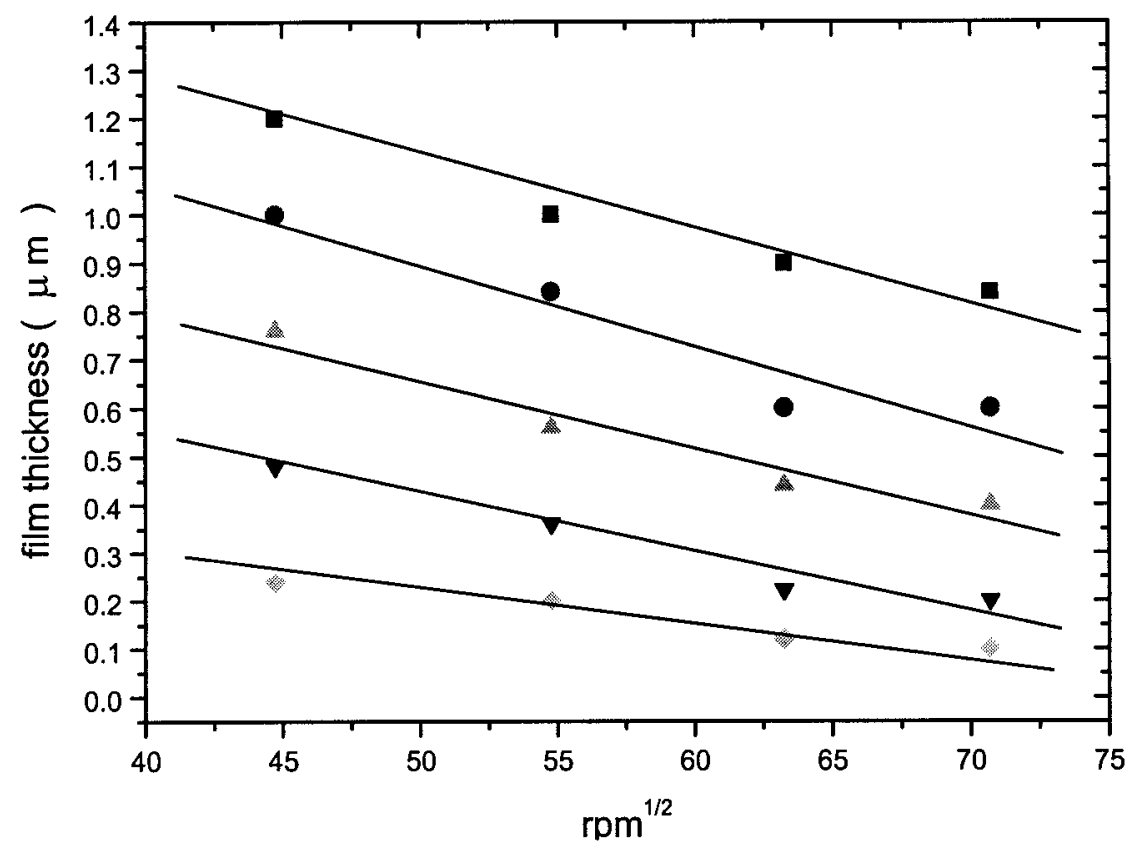

Figure 1 Dependence of film thickness of spin-coated resist $A$ on spinning rate at various solid contents of polymer in $10 \mathrm{~g}$ PGMEA: $\boldsymbol{\square}, 2 \mathrm{~g} ; \boldsymbol{\bullet}, 1.8 \mathrm{~g} ; \boldsymbol{\Delta}, 1.5 \mathrm{~g} ; \boldsymbol{\nabla}, 1.2 \mathrm{~g} ; \diamond, 1 \mathrm{~g}$.

concentration or by changing the spin rate. Samples were exposed to lambda-physik $\mathrm{KrF}$ and $\mathrm{ArF}$ excimer lasers through a $1-\mu \mathrm{m}$ line and space (L/S) contact mask, and were then subjected to a postexposure bake (PEB) at $120^{\circ} \mathrm{C}$ for $1 \mathrm{~min}$. Resists were developed on tetramethylammonium hydroxide (TMAH) developer and then rinsed in water for $10 \mathrm{~s}$.

\section{RESULTS AND DISCUSSION}

\section{Characteristics of Photoresists}

The monomer feed ratio and physical properties of the photoresist copolymers $A$ to $H$ are listed in Table I. The MAA content was kept at $20 \mathrm{~mol} \%$ for all copolymers because it was previously reported to have optimum sensitivity to polarity change. ${ }^{4,5,7-10}$ The copolymers were prepared through free-radical polymerization with the same amount of AIBN initiator. Therefore, the molecular weights of the copolymers are similar in spite of the composition variation. The $T_{g}$ of copolymers increased as the IBMA monomer was introduced into the system. Variations of their $T_{g}$ 's were correlated and followed the mixing rule of their components. The IBMA incorporated in the resist was chosen as a modifying segment to increase the RIE resistance ${ }^{2,4}$ of the copolymer. The $T_{g}^{\prime}$ 's of the resultant resists in- creased with an increase of IBMA content resulting from the bulky side group of IBMA. The thermal stability of the resists, determined by thermogravimetric analysis (TGA), demonstrated a twostage degradation. The first stage of degradation, in which the $t$-butyl group degrades into $t$-butylene species, shifted slightly with varying compositions. The onset degradation temperature $\left(T_{d}\right)$ was around $200^{\circ} \mathrm{C}$.

The resists were spin-coated on wafers and the effects of solid contents and spin rate on the film thickness are shown in Figure 1. The film thickness of the copolymers varies with the 1 power of solid contents and the $-\frac{1}{2}$ power of the spin rate. ${ }^{27}$ The spin-coated film displayed poor adhesion to the wafer and resulted in a rugged surface when the IBMA was above $40 \mathrm{~mol} \%$. This result indicates that further increasing IBMA content in copolymer is not beneficial for the resist. To obtain a 1- $\mu \mathrm{m}$-thick spin-coated film for the following investigation, the solution of $2 \mathrm{~g}$ solid/10 $\mathrm{g}$ PGMEA with the spin rate of $3000 \mathrm{rpm}$ was followed for this system.

\section{Deprotection Kinetics}

The broadening of $\mathrm{C}=\mathrm{O}$ around $1700 \mathrm{~cm}^{-1}$, the blue shift of $\mathrm{C}-\mathrm{O}-\mathrm{C}$ around $1150 \mathrm{~cm}^{-1}$, and the decrease of $\mathrm{C}-\left(\mathrm{CH}_{3}\right)_{3}$ around $1368 \mathrm{~cm}^{-1}$ in the FTIR spectra is characterized as the deprotection 


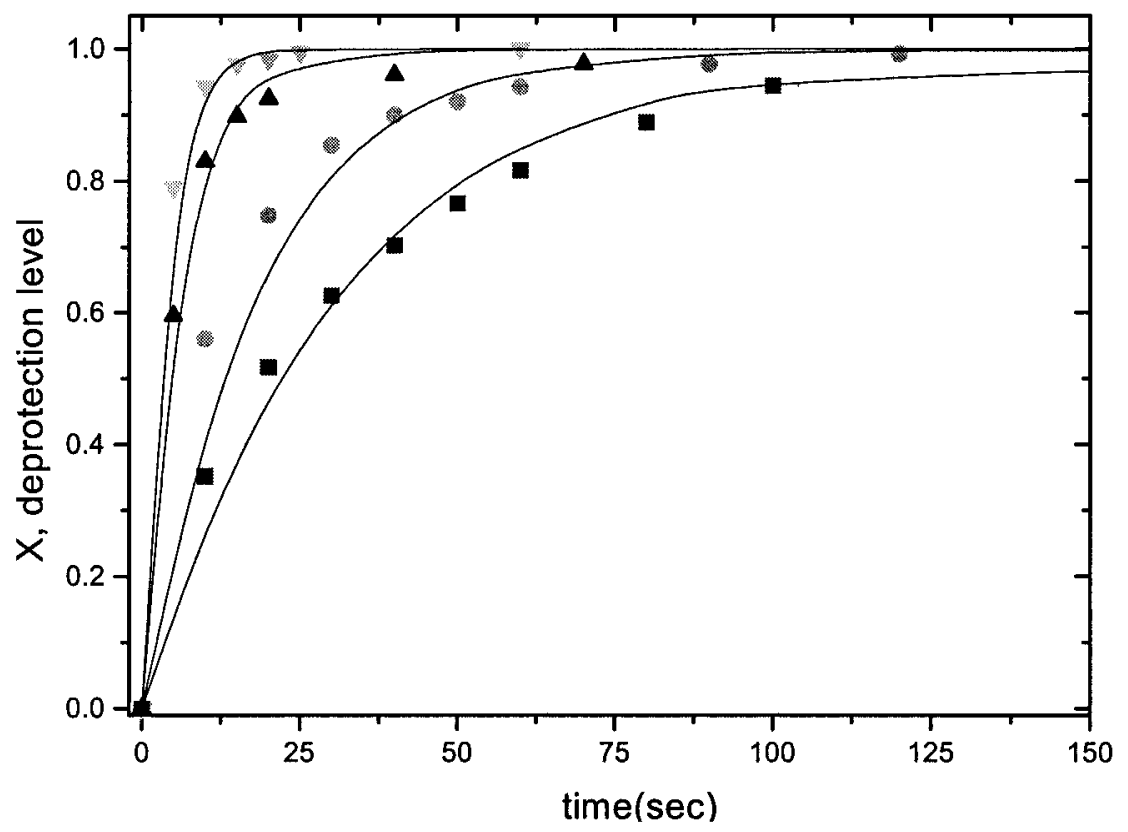

Figure 2 Deprotection level versus time at different temperatures: $\mathbf{\square}, 100^{\circ} \mathrm{C}$; $105^{\circ} \mathrm{C} ; \boldsymbol{\Delta}, 115^{\circ} \mathrm{C} ; \nabla, 120^{\circ} \mathrm{C}$.

of the $t$-butyl group in the methacrylate resist. ${ }^{7,24,25}$ The deprotection level is defined as

$$
\text { Deprotection level } X=\frac{[\mathrm{COOR}]_{0}-[\mathrm{COOR}]}{[\mathrm{COOR}]_{0}}
$$

The mercury lamp was used for exposure and the concentration of stimulated photoacid was as- sumed to be constant with a long-time exposure under verification by phototitration techniques. ${ }^{26}$ First-order approximation of the deprotection reaction rate to the $t$-butyl content is expressed as

$$
\frac{-d[\mathrm{COOR}]}{d t}=k\left[\mathrm{H}^{+}\right]^{a}[\mathrm{COOR}]=k_{1}[\mathrm{COOR}]
$$

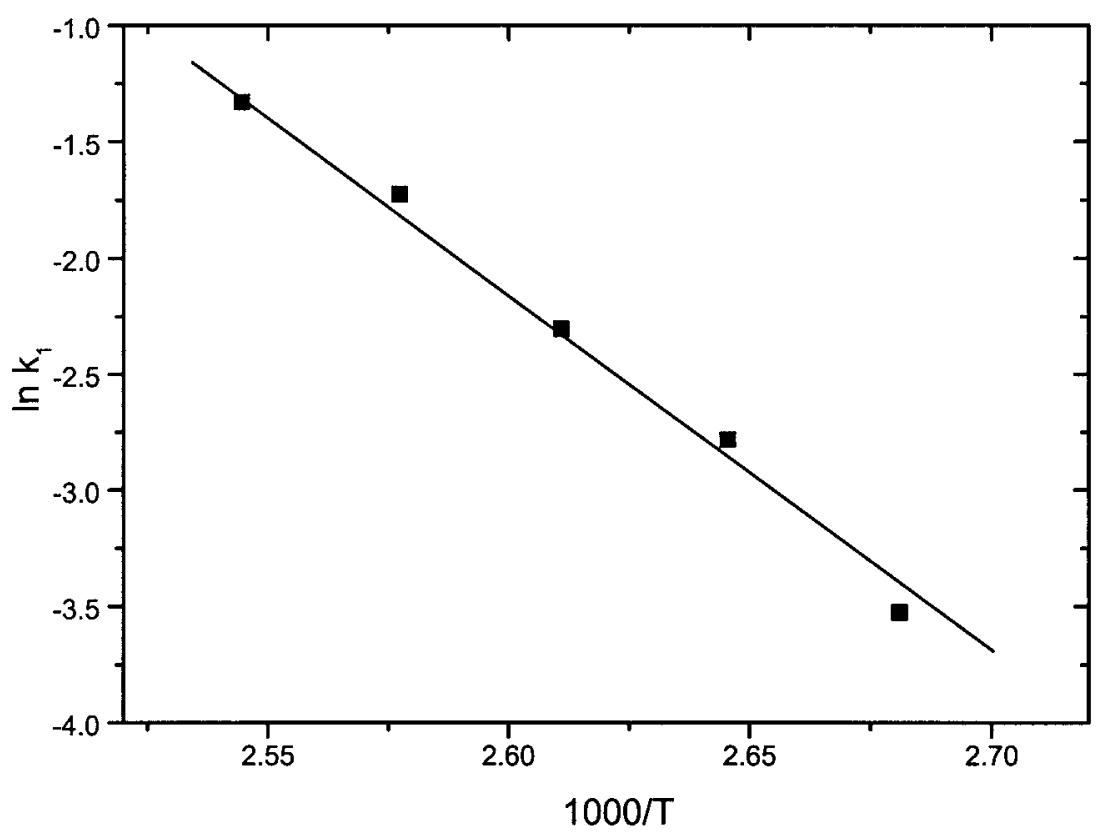

Figure 3 Arrhenius plot of deprotection rate constant versus temperature. 


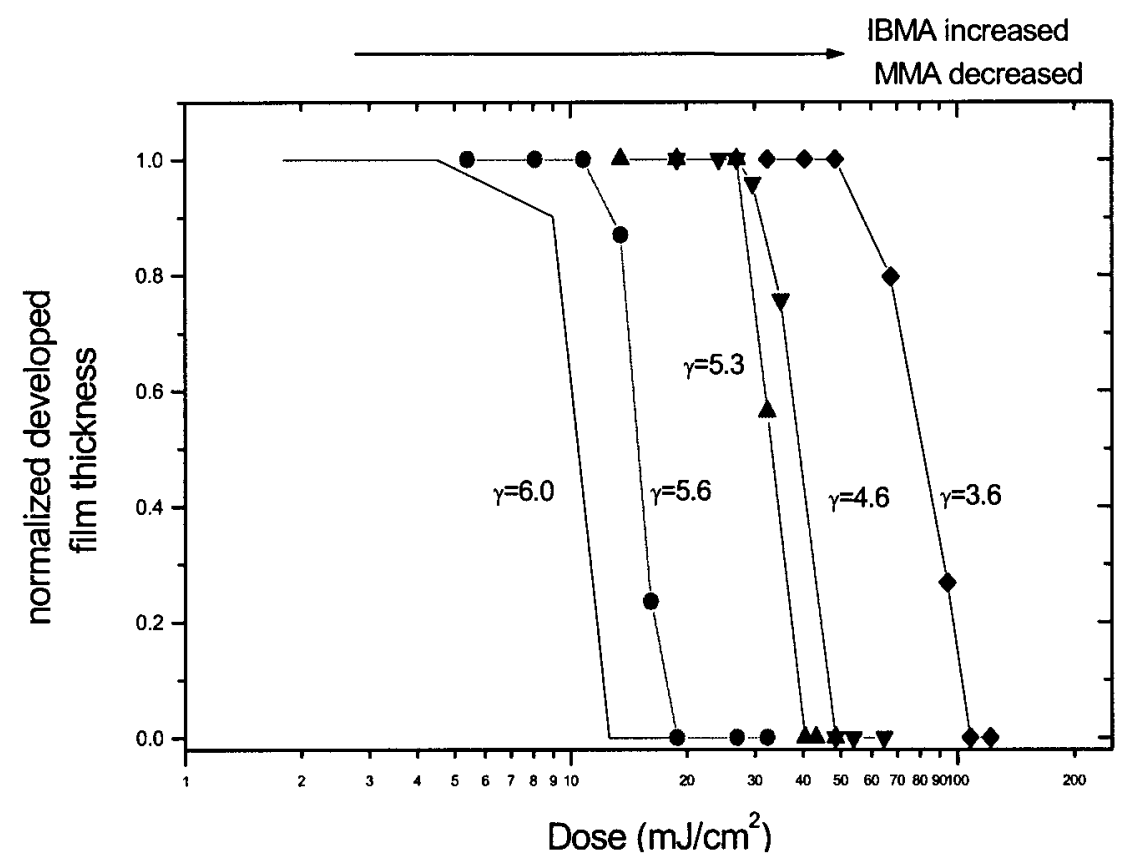

Figure 4 Contrast curves of $\boldsymbol{\square}$ resist $A$, - resist $B, \boldsymbol{\Delta}$ resist $C, \boldsymbol{\nabla}$ resist $D$, and $\bullet$ resist $E$ exposed to 248 -nm light and developed with $0.065 N$ TMAH for $10 \mathrm{~s}$.

where $[\mathrm{COOR}]$ and $\left[\mathrm{H}^{+}\right]$represent the relative concentration of the $t$-butyl group and photoacid, respectively.

The fitting curves of the deprotection level $X$, as shown in Figure 2, are found to correlate well with the experimental data. The Arrhenius plot of the kinetic constant $k_{1}$ to the reciprocal of temperature is illustrated in Figure 3. The activation energy for deprotection of the $t$-butyl group of methacrylate was obtained as $31.1 \mathrm{kcal} / \mathrm{mol}$ in the

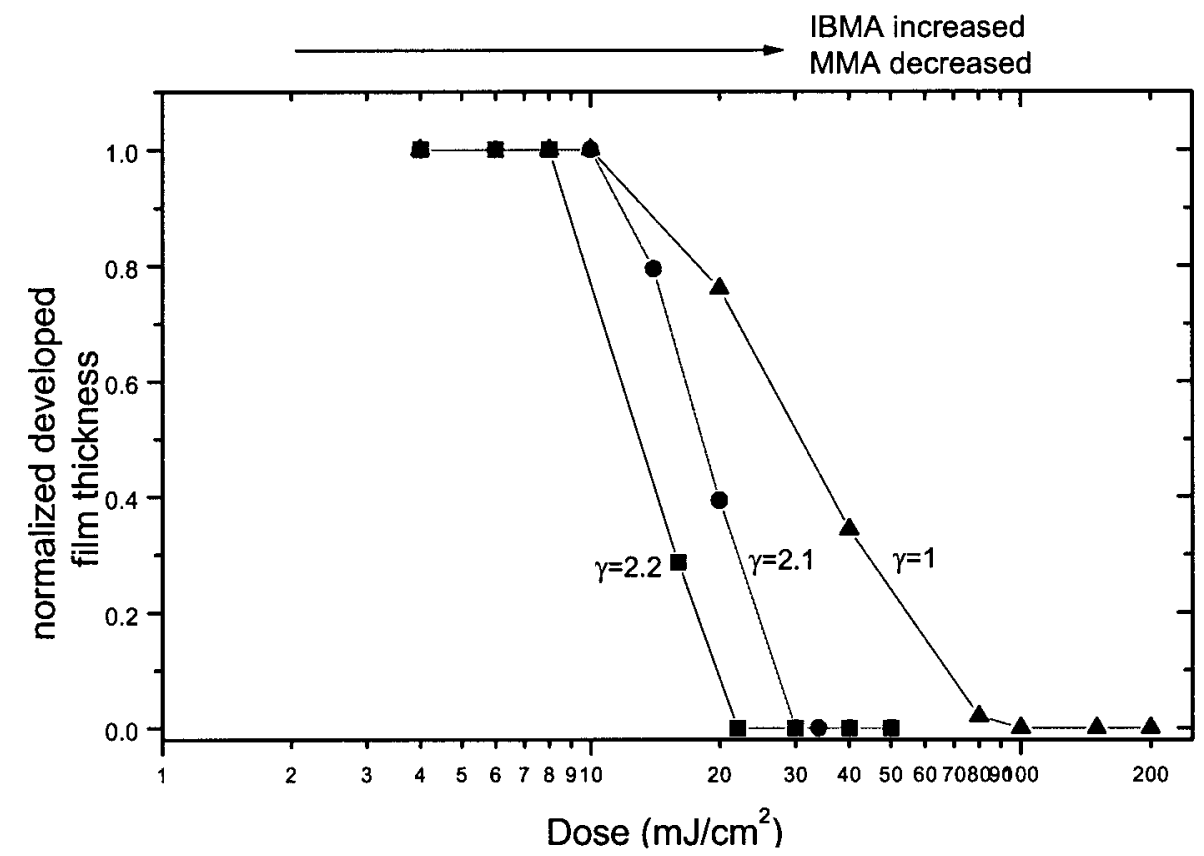

Figure 5 Contrast curves of $\boldsymbol{\square}$ resist $A$, resist $B$, and $\boldsymbol{\Delta}$ resist $D$ exposed to 193 -nm light and developed with $0.065 \mathrm{~N}$ TMAH for $10 \mathrm{~s}$. 

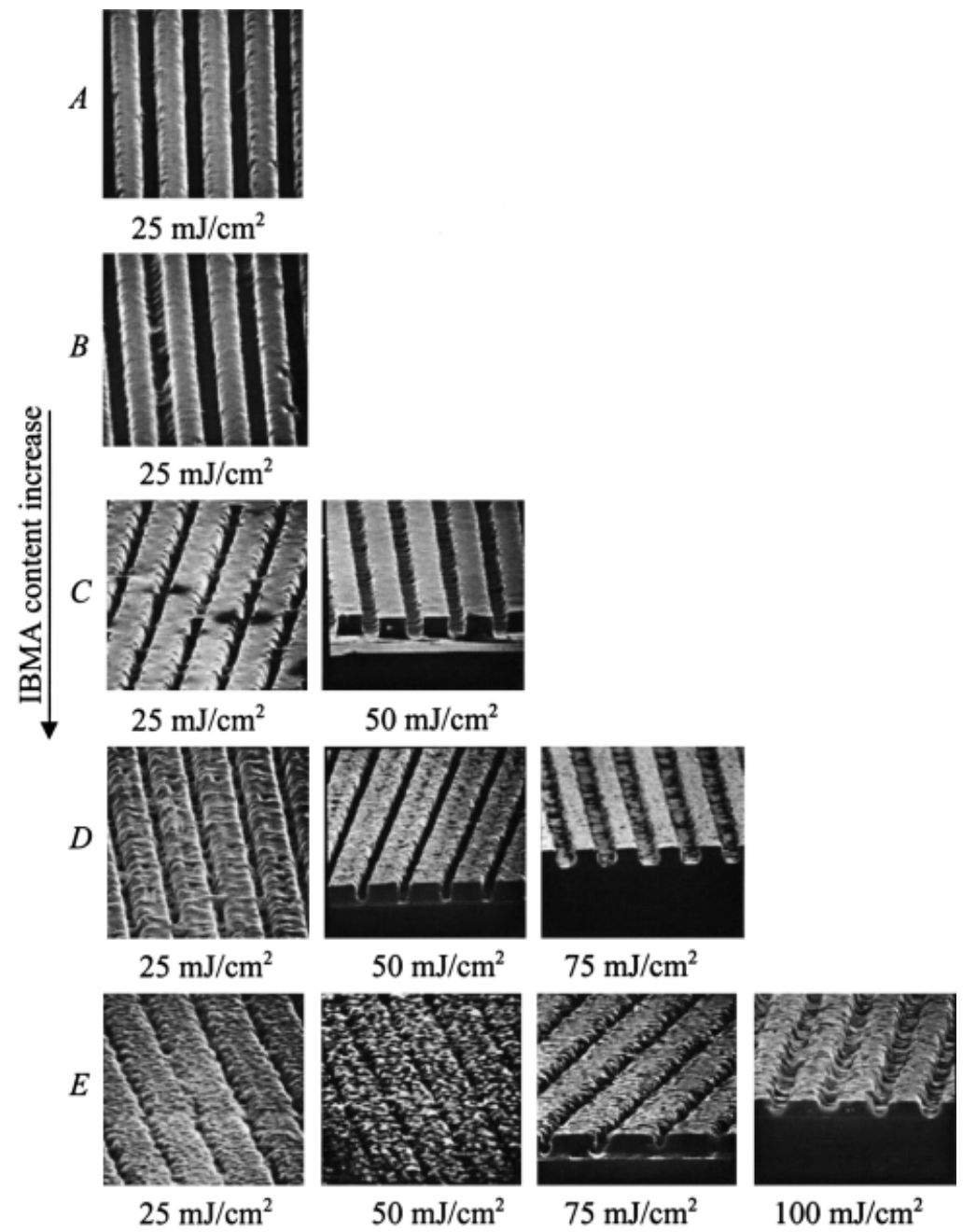

Figure 6 Lithographic pattern of resists exposed with various energy doses and developed with $0.0615 \mathrm{~N}$ TMAH for $20 \mathrm{~s}$.

film. The saturation of deprotection was found in Figure 2 for $60 \mathrm{~s}$ at $120^{\circ} \mathrm{C}$. The condition was used to characterize the performance of the resists.

\section{Lithographic Performance}

The conventional developer of $0.26 \mathrm{~N}$ TMAH is usually applied for Novolac and PHS photoresists. However, the developing rate for this system was too rapid to measure the remaining film thickness and even unexposed resist was soluble in the developer. A diluted developer was used and proved to work well in our previous investigation. ${ }^{7}$ The contrast of the resists was measured from the slope of the remaining film thickness after being developed by $0.065 \mathrm{~N}$ TMAH developer for $10 \mathrm{~s}$ at the various exposure doses of 248-nm light source. The sensitivity $E_{0}$ was measured as the minimum energy required for the exposed film beginning to be dissolved in the developer, the results of which are listed in Table I.

The effects of the IBMA content on the contrast curve and light sensitivity of the resists ( $A$ to $E$ ) are displayed in Figure 4 . The resist with IBMA content above $40 \mathrm{~mol} \%$ cannot give a smooth film and, therefore, the pattern of the resist $F$ cannot be resolved in the experiment. The increase of IBMA content in the copolymers reveals a decrease of contrast and sensitivity of the resist. This result can be attributed to the bulky isobornyl group in IBMA, which resulted in absorbing the incident light and inhibiting the diffusion-reaction mechanism. Use of a 193-nm light source instead of $248 \mathrm{~nm}$ for the resists was also investigated and the resultant contrast 


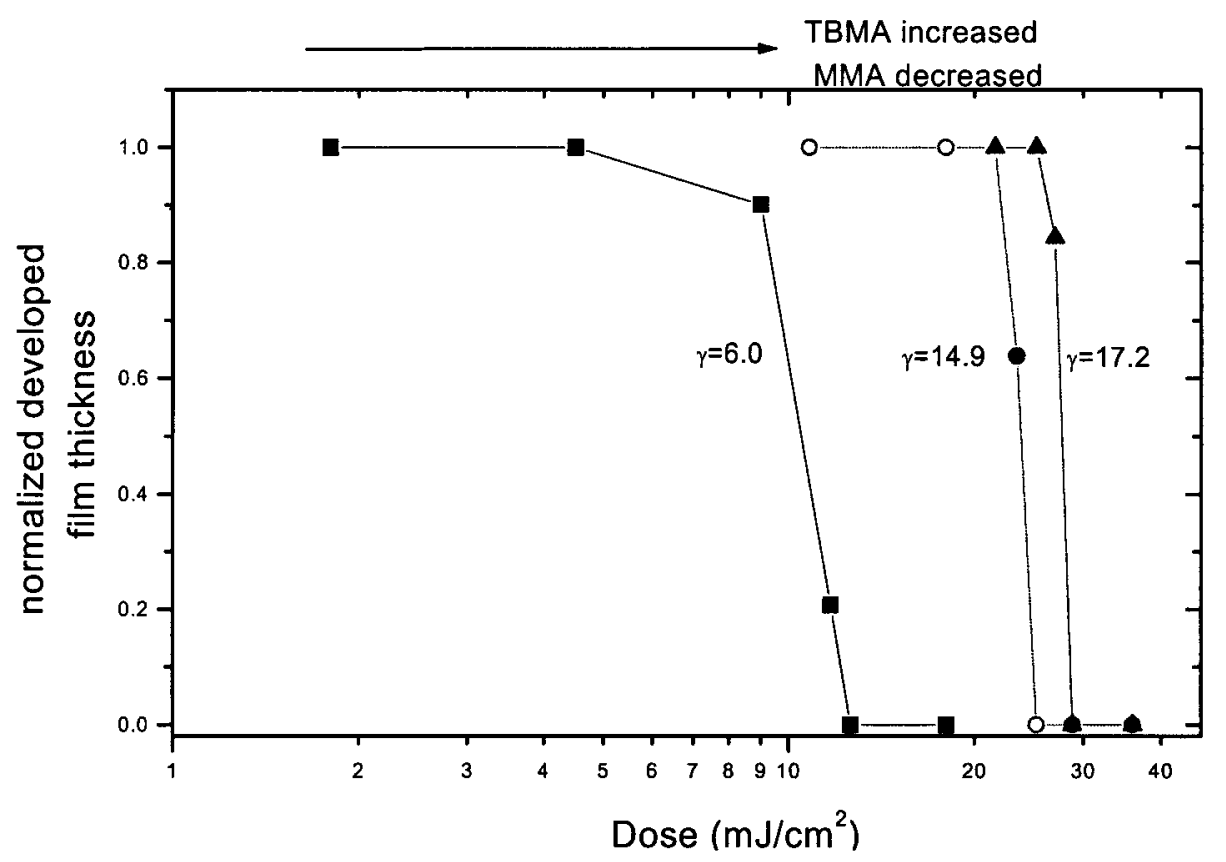

Figure 7 Contrast curves of $\square$ resist $A$, resist $G$, and $\boldsymbol{\Delta}$ resist $H$ exposed to 248 -nm light and developed with $0.065 \mathrm{~N}$ TMAH for $10 \mathrm{~s}$.

curves are shown in Figure 5. Comparing the contrast curves in Figures 4 and 5, contrasts were significantly decreased by using a 193-nm light source, and this finding may be attributed to the strong absorption of the PAG under exposure with a 193-nm light source. The fast decay of photons in the film would result in the decrease of the contrast. Therefore, a clearer pattern can be transferred by exposing the resists with a $248-\mathrm{nm}$ light source than by exposing with a 193-nm light source.

The resists were exposed with different doses and the lithographic patterns are displayed by SEM in Figure 6. Resists $A$ and $B$ can be developed well, using the exposure dose of $25 \mathrm{~mJ} / \mathrm{cm}^{2}$. However, the resist requires a further dose of about $25 \mathrm{~mJ} / \mathrm{cm}^{2}$ for a further increase of $10 \%$ IBMA content in the resist. The introduction of the isobornyl group of IBMA into the resist will increase the $T_{g}$ of the copolymer resist. The free volume of the resist available for photoacid diffusion is decreased ${ }^{16}$; thus, the exposure energy required for the photoacid is increased.

The effect of the TBMA content in the resist on the contrast curves is shown in Figure 7. The greater the TBMA content in the resist, the more energy is needed to stimulate more photoacid to accelerate the deprotection reaction. The contrast value elevates with the increase of TBMA content in the resist. Figure 8 shows the lithographic patterns by SEM for resists $A, G$, and $H$. The pattern of resist $H$, which has the lowest sensitivity and the highest contrast value among the three resists, was easily stripped off the wafer in just $20 \mathrm{~s}$. The smallest processing window among the three resists is found for resist $H$. The patterns shown in Figure 8 imply that the greater the TBMA content in the resist, the easier the activated photoacid diffuses from the exposed area to the unexposed area. It will subsequently change the polarity of the unexposed region during the postbaking. Thus, the diffusion of photoacid from the exposed area to the unexposed area should also play an important role in lithography.

RIE is a process to etch the substrate by plasma after the exposed resist has been developed. The unexposed resist may also be etched at the same time. The IBMA incorporated in the resist is expected to increase the RIE resistance. The effect of the IBMA content on the physical (Ar) and chemical $\left(\mathrm{CHF}_{3}\right)$ resistance is shown in Figure 9. As we expected, as the IBMA content increases in the resist, the RIE rate decreases in argon and $\mathrm{CHF}_{3}$ atmospheres.

The sensitivity of the resists measured by the plane exposure method can be obtained from the contrast curve. However, more information is needed to evaluate lithographic performance, 

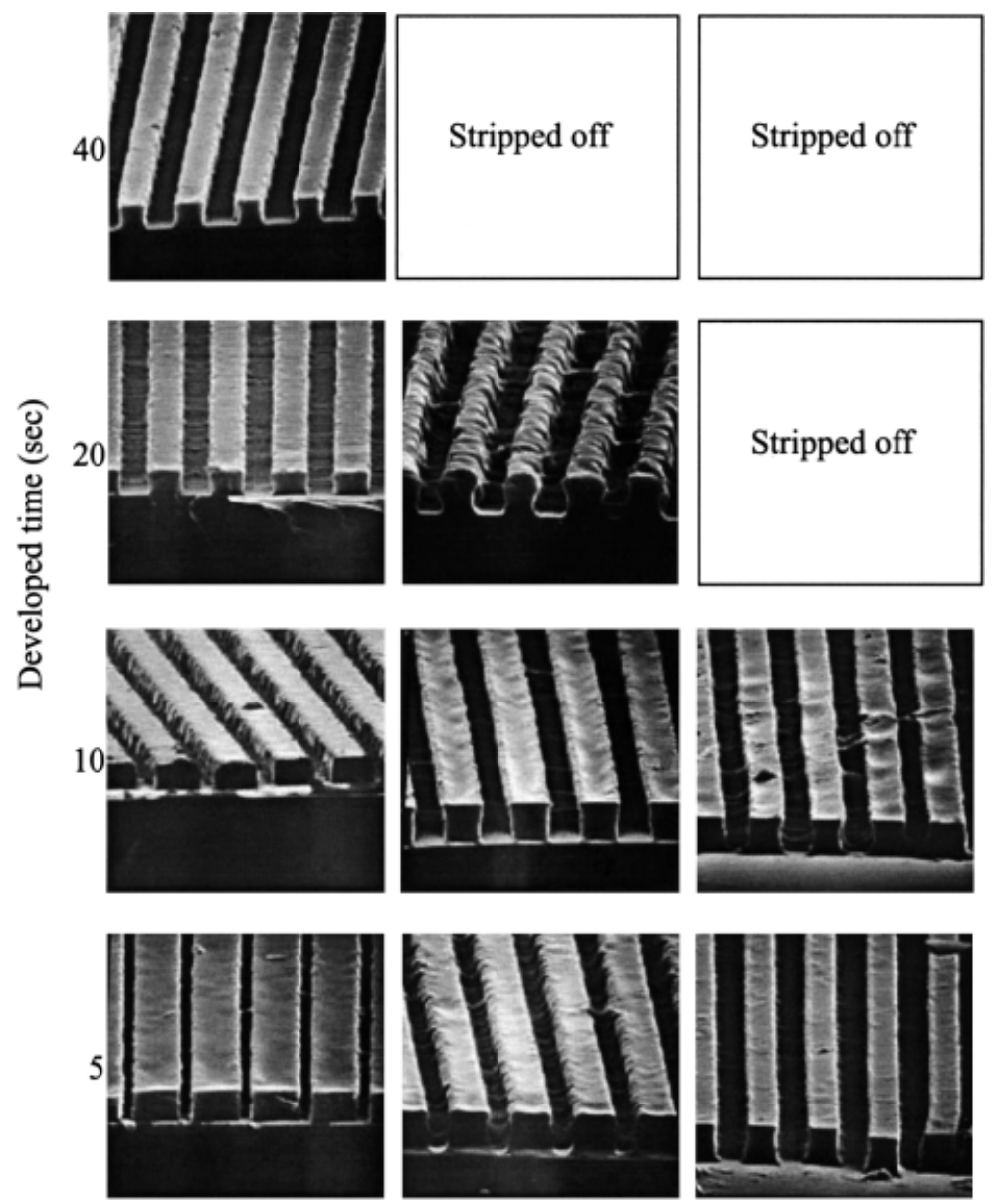

$A(30 \%$ TBMA)

$G(40 \%$ TBMA $)$

$H(50 \%$ TBMA $)$

Figure 8 Lithographic pattern of resists of various TBMA contents at various developed times. Developer: $0.0615 \mathrm{~N}$ TMAH; exposure energy: $25 \mathrm{~mJ} / \mathrm{cm}^{2}$.

such as $T_{g}$, developing rate, and stability of the resist. Photoacid diffusion plays an important role in the resist chemistry. The diffusion-reaction process is used to resolve the depth of focus (DOF) and standing wave effect. However, the photoacid diffusion may vary with the extent of reaction and is hard to measure in the experiment. We cannot judge the performance simply from the contrast curve because it is an oversimplified experiment that the photoacid diffusion is not considered. Although the contrast curves and lithography performance in the research demonstrate that the processing feasibility decreases with the higher IBMA content in the resist, the RIE process shows that the resist of higher IBMA content can withstand the etching in the process. Therefore the trade-off technique or modification of recipes (such as adding some dissolution inhibitor or crosslinking agent) is required to formu- late a suitable resist. From this experiment, the resist with 10 to $20 \%$ IBMA content and $30 \%$ TBMA content is evaluated to be the most suitable composition for the best lithographic performance.

\section{CONCLUSIONS}

The methacrylate resists with TBMA as acid-labile group and IBMA as anti-RIE group were found a suitable composition for the lithographic performance of resists. The $T_{g}$ 's of copolymers were shown to meet the rule of mixture. The film thickness of a spin-coated resist is observed to be reciprocally proportional to the square root of the spin rate and proportional to the polymer concentration. The positive-tone images are observed in the experiments. The deprotection kinetics of the 


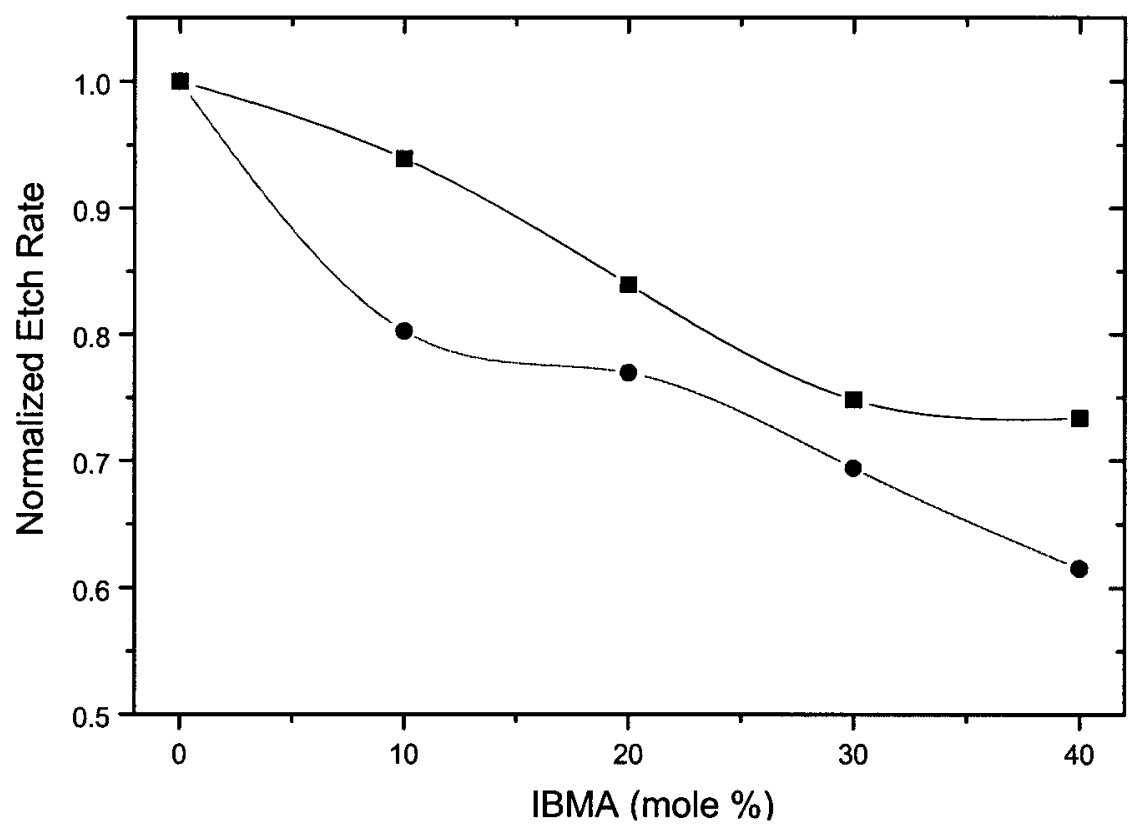

Figure 9 Effect of IBMA content on the RIE resistance under $\mathrm{CHF}_{3} \mathbf{a}$ and $\mathrm{Ar}$ atmospheres.

$t$-butyl group of TBMA in the resist using FTIR analysis was proved to proceed as a first-order reaction to the TBMA concentration, with an activation energy of $31.1 \mathrm{kcal} / \mathrm{mol}$. The increase of IBMA content in the resist increases the $T_{g}$ of the resist and improves its reactive ion etching (RIE) resistance, although the sensitivity and contrast of the resist decrease at the same time. In addition, the increase of TBMA content in the resist will decrease the sensitivity and increase the contrast but result in a smaller processing window. Only with critical tailoring of the resist composition can the perfect lithography be achieved.

\section{REFERENCES}

1. Allen, R.; Wallraff, G.; Dipietro, R.; Hofer, D.; Kunz, R. J Photopolym Sci Technol 1994, 7, 507.

2. Rothschild, M.; Forte, A. R.; Kunz, R. R.; Palmateer, S. C.; Sedlacek, J. H. C. IBM J Res Develop 1997, 41, 49.

3. Hiro, M.; Akahori, T.; Tachiki, S. Polym Prepr (Am Chem Soc Div Polym Chem) 1997, 38, 137.

4. Allen, R. D.; Wallraff, G. M.; Hofer, D. C.; Kunz, R. R. IBM J Res Dev 1997, 41, 95.

5. Jung, J. C.; Bok, C. K.; Bail, K. H. Proc SPIE-Int Soc Opt Eng 1998, 3333, 11.

6. Ito, H. Proc SPIE-Int Soc Opt Eng 1999, 3678, 2.

7. Fu, S. C.; Hsieh, K. H.; Wang, L. A. J Polym Res $1999,6,2$.
8. Nakano, K.; Iwasa, S.; Maeda, K.; Hasegawa, E. Proc SPIE-Int Soc Opt Eng 1998, 3333, 43.

9. Allen, R. D.; Opitz, J.; Ito, H.; Wallow, T. I.; Casmier, D. V.; Dipietro, R. A.; Brock, P. J.; Breyta, G.; Sooriyakumaran, R.; Larson, C. E.; Hofer, D. C. Proc SPIE-Int Soc Opt Eng 1999, 3678, 66.

10. Gokan, H.; Esho, S.; Ohnishi, Y. J Electrochem Soc 1983, 130, 143.

11. Takahashi, M.; Takechi, S.; Kaimoto, Y.; Hanyu, I.; Abe, N.; Nozaki, K. Proc SPIE-Int Soc Opt Eng 1995, 2438,422.

12. Nakano, K.; Maeda, K.; Iwasa, S.; Ohfuji, T.; Hasegawa, E. Proc SPIE-Int Soc Opt Eng 1995, 2438, 433.

13. Allen, R. D.; Sooriyakumaran, R.; Opitz, J.; Wallraff, G. M.; DiPietro, R. A.; Breyta, G.; Hofer, D. C.; Kunz, R. R.; Jayaraman, S.; Shick, R.; Goodall, B.; Okoroanyanwu, U.; Wilson, C. G. Proc SPIE-Int Soc Opt Eng 1996, 2724334.

14. Maeda, K.; Nakano, K.; Iwasa, S.; Hasegawa, E. Proc SPIE-Int Soc Opt Eng 1997, 3049, 55.

15. Dammel, R. R.; Ficner, S.; Oberlander, J.; Jacobs, A. K.; Padmanaban, M.; Khanna, D. N.; Durham, D. L. Proc SPIE-Int Soc Opt Eng 1998, 3333, 144.

16. Toriumi, M.; Ohfuji, T.; Endo, M.; Morioto, H. Proc SPIE-Int Soc Opt Eng 1999, 3678, 368.

17. Itani, T.; Yoshino, H.; Hashimoto, S.; Yamana, M.; Smoto, N.; Kasama, K. J Vac Sci Technol B 1996, $14,4226$.

18. Mack, C. A. Inside Prolith; Finle Technologies, Inc., 1997. 
19. Zuniga, M.; Neureuther, A. R. J Vac Sci Technol B 1995, 13, 2957.

20. Sekiguchi, A.; Mack, C. A.; Isono, M.; Matsuzawa, T. Proc SPIE-Int Soc Opt Eng 1999, 3678, 985.

21. Allen, R. D.; Wallraff, G. M.; Dipietro, R. A.; Hofer, D. C.; Kunz, R. R. Proc Am Chem Soc Natl Symp 1995, 72, 100.

22. Kunz, R. R.; Allen, R. D.; Hinsberg, W. D.; Wallraff, G. M. Proc SPIE-Int Soc Opt Eng 1993, 1925, 167.

23. Allen, R. D.; Wallraff, G. M.; Hinsberg, W. D.; Simpson, L. L.; Kunz, R. R. in Polymers for Microelectronics; Thompson, L. F.; Willson, C. G.; Ta- -gawa, S., Eds.; ACS Symposium Series 000; American Chemical Society: Washington, DC, 1994.

24. Hutchinson, J. M.; Wallraff, G. M.; Hinsberg, W. D.; Opitz, J.; Oldham, W. G. Proc SPIE-Int Soc Opt Eng 1995, 2438, 486.

25. Petersen, J. S.; Mack, C. A.; Thackeray, J. W.; Sinta, R.; Fedynshyn, T. H.; Mori, J. M.; Byers, J. D.; Miller, D. A. Proc SPIE-Int Soc Opt Eng 1995, 2438, 153.

26. Buhr, G.; Dammel, R.; Lindley, C. R. Polym Mater Sci Eng 1989, 61, 269.

27. Willson, C. G. in Introduction to Microlithography; Thompson, L. F.; Willson, C. G.; Bowden, M. J., Eds.; American Chemical Society: Washington, DC, 1994. 